\title{
Innovation management from the inside: An approach from attention and everyday praxis
}

\author{
Fran Morente 1 , Xavier Ferràs (iD \\ Universitat de Vic (Spain) \\ fjmp.1984@gmail.com, xavier.ferras@uvic.cat
}

Received February, 2017

Accepted June, 2017

\section{Abstract}

Purpose: We attempt to deepen the understanding of innovation management from the attention and everyday life.

Design/methodology: Following a micro-sociological approach along with social constructivism, qualitative and inductive methods are used. The methodological design responds to the Grounded theory. Focusing on organizational units of innovation management, the empirical sample consists of a central case study coupled with six satellite case studies. For all cases, an in-depth review of corporate documentation is carried out. During 2016, an indepth ethnography had been carried out in the case of a central study, including interviews with each participant; at the end of the year, qualitative interviews were carried out in satellite study cases.

Findings: The research results on an emerging theory establish a transverse movement crisscrossing an organization, which in turn diffuses organizational attention as regards the inputs of innovation, largely contributing to the fact that innovation management units' experience multifocality, and that the agenda of their agents become volatile. In addition, the micro-sociological positioning offers a new vision in managing innovation, regardless of linear or schematic representations. 
Research limitations/implications: The empirical sample includes Spain-based organizations from different sectors. The data structuration and the derived conclusions could vary according to the chosen nation.

Practical implications: Far from abstractions, the paper offers results that enable understanding on innovation management from a realistic perspective. The knowledge of praxis allows a better understanding of innovation management carried out by these organizational units, which are the main nodes of promotion, stimulation and execution of innovation in modern organizations.

Social implications: From the micro-sociology perspective, our focus remains on the importance of agents and the everyday life in the process of building an organization as a collective representation.

Originality/value: The originality of the present study is in two sense: the conceptual framework explores innovation management for the first time through attention; under the methodological framework, we leave aside the hegemonic quantitative-structural approach, to focus the study in the everyday life of Innovation Project Managers (the organizational agents), who actually go on to implement innovation management. Thus, we elude the discursive rhetoric of innovation to cling to the real praxis, that by which organizations will get results and survive.

Keywords: Innovation, Management, Attention, Microsociology, Everyday life, Grounded Theory

Jel Codes: Z13, O30

\section{Introduction}

\subsection{Innovation}

Innovation is just not one of the key factors to the survival of any organization; it is an essential necessity (Kim, 1980; Rothwell, 1994; Zahra \& Covin, 1994; Porter, 1996; Hamel, 2007; Baregheh, Rowley \& Sambrook, 2009; VolkanTürker, 2012; Ryan \& Tipu, 2013). 
Innovation is the source

- of sustained growth (Hogan \& Coote, 2014),

- of successful (Crane and Meyer, 2011; Tidd, Bessant \& Pavitt, 2011),

- of external knowledge and technology (Chesbrough, 2003b; Un, 2011) and

- of competitive advantages (Vila, Pérez \& Coll-Serrano, 2014), which serve to anticipate market needs (Michaud, 2012).

Innovation critically influences in the viability of an organization, thereby justifying its degree of durability over time (Damanpour \& Gopalakrishnan, 1998; Allen, Adomza \& Meyer, 2015), and in the mobilizations of their social and economic structures (Cheng, Chang \& Li., 2013). To put it in terms of Zahra and Covin (1994, pp. 183): innovation is widely considered as the life-blood of corporative survival growth.

Innovation breaks the once-outward wall of an organization; so innovation management must systemize innovation at all organizational levels (Hamel, 2006). It is not enough to detect opportunities, allocate resources, develop and prototype them; all this process must be accompanied by a common cultural basis, an explicit support of top management, a competitive cooperation between employees, etc. (Tidd et al., 2011); holistically put, innovation management, which is usually carried out by a particular organizational unit, in reality should connect -and must be connected right from the Executive President to the last employee in an organizational hierarchy (Hamel, 2007). This core competence is carried out by individuals in an organization. (Amabile, Conti, Coon, Lazenby \& Herron, 1996). Knowingly and efficiently managed, innovation intertwines the constituent elements and transformative factors of the organization to establish a new state of things (Lawson \& Samson, 2001). There is no innovation without management (Hamel, 2007; Tidd et al., 2011; Alter, 2013).

After the introduction of the Ppen Innovation Concept by Henry Chesbrough, it is ironical to even think that organizations can innovate in total isolation (Fagerberg, 2005). The current open innovation landscape is characterized by (Chesbrough, 2003a):

- increasing the mobility of highly qualified professionals;

- abundance of venture capital;

- great knowledge dispersion in a broad diversity of organizations; and 
- the growing capacity of external suppliers.

Working in an open mode, involves the exposure of organizations to an avalanche of information and potential collaborations of the stakeholders' ecosystem; potentialities and opportunities accumulate at the doorstep of the organization (Chesbrough, 2003a). As a result, the attention of innovation management units, whose mission is to channelize innovation in organizations, will be constantly and fiercely tested.

\subsection{Attention}

William Ocasio $(1997,2011)$ conceives the organization as a system of distributed attention; in its metatheory, that deepens in the legacy of Herbert Simon, the critical variable of the cognition, the actions and the organizational changes are not the previous knowledge. What is fundamental are situations and organizational context in which the decision-makers are inserted (Ocasio, 2011). So what configures these situations and contexts is attention, which is defined as follows: [...]noticing, encoding, interpreting, and focusing of time and effort by organizational decision-makers on both (a) issue: the available repertoire of categories for making sense of the environment: problems, opportunities, and threats; and (b) answers: the available repertoire of action alternatives: proposals, routines, projects, programs, and procedures (Ocasio, 1997, pp. 189).

This classic explanation continues to harp on attention as a limited capacity to process information, but gradually, with contributions from neurosciences, a broader vision does open up. Far from a linear unitary process, it is a set of complex neural processes assembled (Ocasio, 2011). This new vision fits better with the capture, assimilation, distribution and execution, that is made of the attention of an organization (Cho \& Hambrick, 2006). In the Attention-Base View (ABV), attention is indeed the most precious asset, and focusing properly is the most important action. On paper, organizations that know how to focus their attention correctly will be more prone to change, adapt to new environments and launch new processes or solutions to the market (Ocasio, 1997). 


\subsection{Innovation $\&$ attention}

It is extremely interesting to analyze innovation management from Ocasio's (2011) perspective of attention; but, what happens to the attention in innovation management? Our ethnographic experience showed us that the conceptualization of Ocasio can perfectly be applied to the study of innovation management in order to understand its internal mechanisms and, at the same time, diagnose the whole of an organization.

If human attention can be limited, the same can be applied to organizational attention too (Ocasio, 1997). Flooded with information, managers are exposed to much more information than they can understand, assimilate and process (Cho \& Hambrick, 2006). Thus, open innovation does more than just multiply the dispersion of organizational attention: knowing the internal capacities and resources, connect and assess potential partners, keep update of the different trends and technologies, find new ways of financing projects, find cross-sectorial alliances, be present in the main debate forums, envision market movements, delegate to mixed teams, create spin-offs, assess the suitability of one decision over another, weigh the risks of certain innovations, monitor economic stability, transfer innovation results, etc. perhaps too much for a single attention.

Thus, open innovation does more than multiply the dispersion of organizational attention: knowing the capacities and internal resources, connecting and valuing potential partners, keeping abreast of the different technologies and trends, finding new ways of financing projects, finding Cross-sectoral alliances, be in the main forums of debate, intuit the movements of markets, delegate to mixed teams, create spin-offs, assess the suitability of one decision over another, weigh the risks of certain innovations, monitor the stability of the account. In other words: to much for a single attention.

With no sign of decreasing, the influx of information is such that, recently, the term infoxication has appeared; infoxication is an overload of information because of new technologies. (Díaz, 2014). For all of this, now more than ever, Michael Porter's ironic dictum -the essence of strategy is choosing what to do (Porter, 1996, pp. 70)- reveals itself to us with the utmost topicality. In the open innovation era, you have to know how to screen, where to focus, and you have to find your own path; it is time to deepen the management of innovation. 


\subsection{Objective \& micro-sociological approach}

Our aim is:

to deepen the understanding of innovation management from the attention and everyday life.

The theoretical models and frameworks often overlook the cultural fragments and social conflicts that occur within organizations (Van Maanen \& Barley, 1985), often blurring the importance of everyday life; in this model, agents are blurred and situation are crushed by the weight of structures as a homogeneous whole (De Certeau, 2006). Godin (2015) states that a model is a simplification whose power lies in creating images based on everyday complexities. Organizational studies in general have this obvious gap: quantitative study and organizational results are the preferred ones. After our direct experience, it is congruent to study innovation management, not from the strategic direction and leadership, but from the inside, that means:

- from innovation management, which is actually carried out by project managers and middle managers, and

- from the experience of everyday attention.

During ethnography, the attention concept is a crucial factor to fully understand and appreciate innovation management. Knowing what happens to attention during innovation management can offer us new ways to understand organizational reality. To banish the image of organization as a monolith (Casey, 2002), it is compulsory to embrace the plural logic (Dorado, 2013) as a living, fluctuating, diverse and unstable entity (Gioia Schultz \& Corley, 2000).

Thus, in order to enrich the analysis, we've based ourselves on micro-sociology. The basic idea of microsociology is [...] to fill in the buman detail missing from abstract representations of buman beings and their societies. The endeavor begins by describing, second by second, the structure/process of social life. The goal is to show the reciprocal relationship between these events and the nature of the society in which they occur, how each causes the other (Scheff, 2007, pp. 3005). Therefore, microsociology focuses on:

- the situation as the main study entity;

- the importance of the interaction order in the socialization between agents;

- emphasis on the elements that make up the common everyday life; and 
- small socialization -as face-to-face talks between two or more agents to a group interaction-as an empirical unit (Collins, 2004).

The micro-sociological approach allows us to

- study innovation management units from their everyday life as an empirical sample limited to structured scientific observation; and

- extrapolate the theoretical inference observed in the mesoscale -group scale- and extrapolate to macroscale -organizational structure- and microscale -organizational agents-.

Focusing our study on this type of innovation management units, we can use miniaturization that Fine and Scot (2011) postulate, whereby situations in groups simulate the foundations and social dynamics of more complex scales and, vice versa, the structural implications have their counterpart in the groups and in their agents.

We study the reality of groups to know the structures and individuals. As De Certeau stated (2006), in the structural fractures is where the poetics of everyday life can be perceived.

\section{Methodology}

\subsection{Social constructivism \& qualitative an inductive method}

Methodologically we choose social constructivism. From this view, objects, individuals, and phenomena exist only through meanings; [...] the reality that matters is what people perceive as important (Taylor \& Bogdan, 1987, pp. 16). Qualitative research was presented for our purpose as the most logical, suitable option. As Yin (2011) emphasizes, qualitative research is not affected by the difficulty of terms and conditions of an empirical sample, the lack of measurement equipment or the lack of historical data, allowing studying the meaning embodied in people in real conditions and represents the particular perspective of the participants. Likewise, with qualitative methods, Eisenhardt (1989) and Creswell (2009) point out, we work with concepts which originate in the phenomenal realities.

With this vision and methods, we deploy the following methodological design. 


\subsection{Methodological design}

\subsubsection{Grounded theory}

The Grounded theory is based on the intercommunication between gathering data under real contexts and analysis. This analysis is carried out through codification of data enabling it to be related for finding new patterns, categories and statements that in amalgamation would create an emergent theoretical construction (Strauss \& Corbin, 1998; Charmaz, 2006). Its aim is to generate theories that reflect better and with greater affinity, rigor and closeness to reality (Glaser \& Strauss, 1967; Strauss \& Corbin, 1998). Social interactions, actions and processes among participants are captured, interpreted, and ordered in theories derived from reality (Creswell, 2009).

\subsubsection{Empirical sample}

In order to deepen our exploration of everyday innovation management in relation to attention, we focus on the study of those organizational units in charge of innovation management; these units, depending on organization, have names such as 'Innovation Department', 'Innovation Management Division', 'R\&D\&I Office', etc. These units are made up by technicians and middle managers, who could be generically grouped as 'Innovation Project Managers'. Although clear interdependencies exist, the inclusion in the empirical sample of High Direction was ruled out; their commitments and their tasks are focused on strategic aspects; on the contrary, with our micro-sociologcal research, we wanted to follow the real praxis, the management of everyday innovation management - de facto-, since it is a hierarchical level and an organizational reality that is little studied in innovation literature, whose emphasis is on leaders and structures. Thus, respecting anonymization agreement signed by the participants and organizations, our empirical simple consists of:

- (a) A central case study (CCS). CCS is the organizational unit in charge of innovation management of a multinational utility, with more than 7.000 employees and an annual investment in innovation higher than 16 million Euros. In the unit, nine participants perform these transversal management tasks. The headquarters are in Spain. Three methods were applied in the CCS:

- Review of corporate innovation documents;

- Intensive ethnography throughout the year 2016; and 
- Qualitative interviews with each participant.

In the following sections, we distinguish their members by A, B, C, and so on.

In order to refute, correct and strengthen the emerging theory, we added:

- (b) Six Satellite Case Studies (SCS). The SCS are organizational units with similar tasks carried out by CCS. For each SCS, all of them in Spain, we take a single person within each case. The sectors of SCS are: utilities, metal SME, multinational consulting, university, non-profit foundation and banking. At SCS, two methods were applied:

- Review of corporate innovation documents; and

- Qualitative interviews of each participant.

In the following sections, we distinguish SCS participants by 1,2, 3, and so on.

While conducting the research with this empirical sample, we applied these methods in a determined order, which in turn allowed us to question and explore reality to construct a new emerging theory.

\subsection{Methodological narrative}

The narrative has three different phases:

\subsubsection{Phase 1 - Gathering data}

Gathering data is the methods used to capture data from reality and feed our methodological design focused on our objective.

Secondary data review: a literature review is always mandatory (Yin, 2011). In addition to rigorous reviews to contextualize our research, looking for gaps, we made a detailed review of numerous corporate documents of innovation in CCS and SCS -i.e. PowerPoints, newsletters, annual reports, intranet, etc.- and also the participants -Twitter account, LinkedIn profile, etc.-. The aim was to know the discourse of innovation management in each case study; the practical side, we would observe if from ethnography. 
Ethnography: ethnography aims to provide rich and holistic perceptions and data about the way of life, culture and interaction space of a particular social group through a detailed time-bound observation, that allow us to understand practices and behaviors in their natural environment and cultural context (Hammersley \& Atkinson, 2007). As Agar (2004) emphasized, as a result of observing reality, we understand analytically the particular point of view of participants, and we find connections. With patience, says Ladner (2014), these connections will raise explanations; if culture is meaning, it is achieved through ethnography. So, throughout 2016, and with a total of 1,704 hours, we ethnographied the CCS following the everyday life of its nine participants from an emic approach. Our ethnography included productive and formal moments -i.e. meetings, committees, presentations, etc.- and unproductive and informal moments -i.e. breakfast, meals, talks, Whatsapp conversations, etc.-. The ethnography was carried out in the headquarters, where CCS participants spend their time. Two periods are distinguished:

- from January to June, an exploratory ethnography was carried out, that is, writing in the field notes. In mid-June, we reached what Glaser and Strauss (1967) called theoretical saturation: the registered situations in the field notes began to repeat and, therefore, we understood the inner point of view of the group.

- from mid-June to December: in this period, as Yin (2011) recommends, assumptions and observations in the field interact productively with literature, discarding, enhancing or taking new paths.

The ethnography began to be oriented towards a concrete phenomenon in certain ways, structuring the reality in concepts.

\subsubsection{Phase 2 - Coding $\&$ interviews}

After the theoretical saturation, coding and gathering coexisted synchronously.

Coding (first versions): Starting in June, we began coding the ethnographic and documentary data of the first half of 2016. The coding proposed by the grounded theory allows us to categorize very different data extracted from reality and to find networks of meaning. The coding versions follow each other, until, gradually, codifications of the data are reached that allow to structure and explain the reality (Strauss \& Corbin, 1998). From June to December, the focused ethnography helped to consolidate coding that would be the basis of our future concepts. 
Interviews: the interviews had the purpose of knowing the intimate point of view of the participants and their world-view (Seidman, 2006), to evaluate - or validate or discard- the coding (Patton, 1989) and to contribute to develop the emergent theory from the participants' plurality (Charmaz, 2006). According to Patton (1989) and Seidman (2006), we looked for the particular narratives, the embodied experience. From the end of October to December, we conducted semi-structured qualitative interviews with all participants, both at the CCS and the six SCS, whose contribution was to set the coding and converge our theoretical assumptions. The interviews were carried out in the same headquarters where innovation management is carried out or, failing that, by telephone, always prioritizing the comfort of the interviewee. For ease of comparison, questions were the same for all participants; beyond the organizational contexts and sectorial differences, we looked for maximum extrapolability of our theoretical concepts. Interviews were the latest input of data to achieve a more robust coding.

\subsubsection{Phase 3 - (Final) Coding \& analysis}

For analysis, we used the five phases of Yin (2011):

- gathering robust data;

- disassembling data and coding;

- reassembling data and hierarchizing them, looking for patterns;

- interpreting in depth; and

- concluding and synthesizing.

In analysis, we took into the account the power of miniaturization. Thus, from the end of 2016 to the beginning of 2017, we did the analysis, whose final output was a final coding to structure the reality and, from this, we can explain it through theoretical concepts anchored in the same reality. 


\section{Results \& discussion}

\subsection{Three-level structure}

Thanks to Grounded theory, the structuration of data follows Figure 1, in which we distinguish three different levels of attention in innovation management.

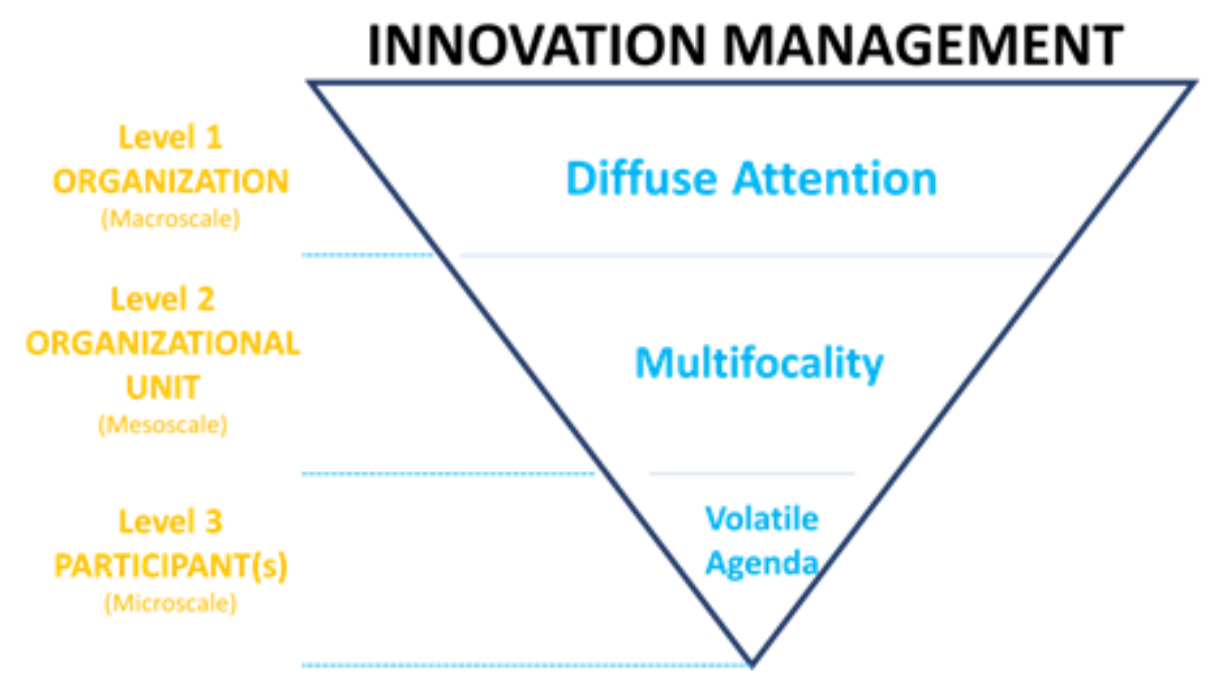

Figure 1. Three-level Structure of Innovation Management

Taking into account what happened during the year of ethnography, and ratified by the interviews, we verified the existence of a cascade movement, from level 1 to level 3: when attention is to diffuse at the organizational level in relation to innovation issues -i.e. strategic orientation towards innovation, networking with partners, speculative opportunities, risk assessment- the focus of innovation management units is multifocal and, at the participant level, agendas become volatile. In this respect, the attention is distributed systematically and structurally at different levels of organizations. Let us go, level by level, to show the emerging concepts. 


\subsection{Level 1 (Organization) - Diffuse attention}

Ocasio (1997) distinguishes between perceptions - detect necessary data- and action -act/decide accordingly with perception-. With Open Innovation, if we take the organization as a whole, attention is diffused when

- the organization's attention has to face a huge crowd of stimuli, whether they are business opportunities, participation in innovation programs, assessment of ideas, study potential collaborators, etc.; and

- has no clear guidelines to prioritize.

Excepting two interviewees, the rest were very clear on that. Participants agree with Chesbrough's (2003a) findings, whereby innovation can only be done in collaboration with external technologies and knowledge. Mainly the inputs come from

- the assessment of trends or technologies potentially implementable in the organization or

- the search for suitable partners to develop innovation projects.

'Another meeting with another possible partner for the $[\mathrm{X}]$ proposal. What a week, dude! And tomorrow more partners to see. I hope to find the best!' (D, 19/V/2016). 'Director Y] has sent an e-mail with [W], [Z] and [S] in copy. He asks for... he wants to get the job done faster! We will assess with [C] to find the logical application in our company.' (F, 3/VI/2016). The avalanche of inputs is very positive, because it shows the effervescence of what innovation entails, but it also makes it difficult for organizations to know if there are no clear-cut framework for action. 'You have to be very clear of what you want and what you're looking for [...]A Company can go crayy if it has no filters, "cause everything comes in"(1, 29/XI/2016). However, all decisions must be made on the basis of a specific context (Ocasio, 1997), and this, in our cases, is not always clear. All participants believe that open innovation is an opportunity to connect with other partners and create new business ideas. However, sometimes, in D's words, 'a filter or a criteria is needed': a strategy applied to innovation management. 


\subsubsection{Ductile strategy}

Ductile strategy consists of a strategy that, far from any rigidity, is capable of changing by exogenous pressures and adapting to different situations or turns of objective. Observed in the CCS and verified in four of six SCSs, the ductile strategy is an option to configure innovation management. In an internal meeting giving feedback to a Direction, D says: 'Strategy is not a map, but a landscape' (D, 28/I/2016). They emphasize that for the leaders of organizations, flexibility and the search for results over the application of a fixed time-process is the priority. There is therefore, a need for value generation; for this reason, both in the CCS and in the SCCs, the participants constantly understand and repeat that innovation cannot remain a mere idea or prototype, but must reach the market or must be applied within the organization. Three months later, in a presentation, B explained his/her innovation management vision: 'The strategy is the latest thing to do. We must to focus on projects. And the whole picture will come later. With the amount of information, you have to be very expeditious deciding what to bet. It is sterile to create and define... great long-terms strategies. We lost too much time... we... we must to go faster. The result do not wait... So the High Direction need to see initiatives aligned with needs, gaps, etc... and the shape the whole thing upwards' (B, 11/III/2016). Due to uncertainties that are always associated with the innovation process, the functional and the search for results are emphasized.

\subsubsection{Result \& iteration}

While we gathered data, we recorded the concept of ductile strategy, wherein an organization is open to all possibilities that may arise internally or externally in collaborative networks in constant transformation, to be able to shape a strategy based on actions. On the positive side, the emphasis on ensuring the tangible results -what CCS participants call 'focus on action'- helps to deploy a process from which results are not achieved. In a departmental meeting, A to the rest: The innovation that they asked for [High Direction] is an innovation with impact, with generation value. To be seen, tangible... Because concepts alone do not help to justify innovation' [...] (A, 20/VII/2016). Another meeting: 'Strategy is focused on more manageable things. Not big strategic lines for a bunch of years, but actions. It a ... a back-and-forth approach. Like design thinking, you know... We do approximations... for... iterations. More than having an over-defined idea of a car, we start with a skateboard, then with a bike, and so on... The definition is step-by-step. I do not know if I explain myself' (C, 3/X/2016). Ductile strategy seeks to obtain 'quick wins' that can justify importance, necessity and significance of innovation, and the best way to reduce uncertainties and economic risk is through iterations. 


\subsubsection{Dispersion}

This strategic approach also has its counterpart. As the strategy is so malleable, fitting and valuing certain opportunities is not always obvious; if the strategy of innovation management is based on actions that are under way, how to carry out the prioritization? This strategy that seeks to reduce risks and to overcome the expense through speed, action and iteration, can lead, paradoxically, to the situation of which it intends to flee. During a coffee-break: T have a bad feeling... Doing a lot of thing, but nothing comes. I do not know if it is the right direction' (E, 21/XI/2016). Two days later: I cannot asses this [a potential idea from an external partner]. What can I say? I have no idea... if this subject matters or not' (D, 23/XI/2016). By failing to establish the criteria to focus on attention - a solid strategy to adhere to-, it will be organizationally oriented to divide the attention into very different topics; all dispersion of attention, recalls Ocasio (2011), entails waste of resources in unnecessary efforts.

\subsection{Level 2 (Organizational unit) - Multifocality}

Because of the first level, and as we narrowed our focus on the group level, we observe the existence of the concept multifocality. By multifocality we mean the property of an organizational unit by which its members are simultaneously involved in a great number of interdependent things that divide their attention in different fronts; things that, far from being automatic in their execution, require what March and Simon (1958) called problem solving or productive thinking. That is to say, each thing of innovation to manage needs inventiveness to solve it. Within multifocality, we distinguish three constituents in the everyday life of this type of units:

- open fronts;

- fragmented vision; and

- planning in the making.

Let's see them. 


\subsubsection{Open fronts}

The term open front is the most immediate correlate of multifocality. This concept refers to the situations in which, due to a number of issues underway, very active attention is required. We find two examples in the following situations. In a meeting: Let's focus! It's what we need. To put some order because we have a lot of open fronts to close' [...] (A, 5/IV/2016). A month later, in the restaurant: I already told you!We are always involved in a lot of things at the same time. Call for ideas, project proposal, and send Doodle to close agendas, lateral meeting, contrast opinions, budgets... I already told you: there's no time to get bore' (B, 19/V/2016). This concept tinged with a certain degree of stress denotes the nature of the work they do: innovation must become tangible; the idea must take shape until it becomes a business opportunity and this must be transformed in a product or a service. In the open fronts, we observe what Ocasio (1997) called, with certain goffmian echoes, situated attention. In their decisions, participants are never subtracted from the organization's internal knowledge, values and beliefs; they embody the organizational cognitive context. With open fronts, Innovation Project Managers refer not only to the amount of work in a given space of time, but also the openness of the task. Open fronts will be triply opened:

- open as far as goal (definition and scope);

- open in terms of process (execution and necessary resources) and

- open in terms of the organizational agents or external partners to be involved at any given time.

The openness of the innovation management's task, forces these units to accept that, as they work harder on their task, the initiative tends to define in itself and its details to be fulfilled; as we observed in the ethnography and in the interview, the Innovation Project Managers need to persevere in their task, clarifying boundaries, scopes, and the main features. To focus on attention (Ocasio, 1997), the openness of tasks complicates the selective focus, being tasks whose contexts, margins and attributes are not fully known at any time. Although presented as a linear process, innovation management is never actually linear (Tidd et al., 2011); it faces sudden advances, setbacks and continuous corrections of trajectory, as part of an approximate idea that needs to be concreted and materialized. The open fronts, as we shall see, require an excellent organization of organizational unit work-time to distribute the overabundance and complexity of the task. To the complexity of working in openness, we can add the interdependence of these units with other organizational units. Innovation management is never done without the intervention of expertise or the support of other organizational units; it is, therefore, as Alter (2011) suggests a highly social process. This collective effort will vary over time; to keep on 
going these units include or exclude certain organizational agents, according to their contribution to sharpen the proposal. Thus, attention of innovation management units will be dispersed in different tasks -or fronts-, whose margins or definition, action and coordination will not be, at the outset, be neither known nor accurate.

\subsubsection{Fragmented vision}

The fragmented vision is the inability to see at the same time what happens in an organization, either by agglomeration of elements, either by its invisibility or by the lack of communication. We decipher two types of fragmentation:

- external fragmented vision: the incomplete view that the organizational unit has of the innovation initiatives that are carried out in the whole of the organization without its intervention; and

- internal fragmented vision: the group's partial view of its own tasks and agendas of its members.

The external fragmented vision is a consequence of the size of the organization; as observed ethnographically, and according to the interviews with SCCs, greater the size and organizational complexity, the more fragmented will be the vision of what happens. During a breakfast meet, the CCS's participants talk about 'things' that are beyond their control. 'Yes, of course, of course, but it's normal, you know. Our company is big, too big... too many things happen at the same time. It's normal: we cannot see all! So many things are invisible, escaping from our control. It's a learning process, little by little, right? I don't know how we can see all the initiatives in innovation. It's a hard, hard thing' [...] (C, 14/I/2016). Several months later, in another meeting: 'Yes, there a lot of things going on... a lot of projects. When you make a list with post-its you realize that next to you someone is working in something that you do not know! In an enormous company, it is impossible, you know, to get a total order (D, 28/VI/2016). Three of SCSs said the same; the dynamism of modern organizations and their size, make it difficult for these units to control everything that happens around innovation. Their vision is doomed to be biased. Information in groups, according to Fine (2012), is always fluctuating; hence, precisely, the internal fragmented vision. Each member demonstrates autonomy in the execution of his/her tasks. Both in the CCS and in the SCS, each participant is dedicated to his/her tasks, puts maximum attention in them and, in the background, will follow as much as possible the tasks of his colleagues. Given, as we have seen, multifocality and the openness of 
innovation management tasks, constant updating among members is impossible. Meetings and breakfasts becomes an improvised updates meetings. Due to the social complexity that depends on other units of the organization or on external partners, the tasks of innovation advance, pause and stop (Tidd et al., 2011). The members of these management units will never have a full and up-to-date knowledge of all the tasks performed by their colleagues; they act as decentralized individualities in combination.

\subsubsection{Planning in the making}

Closely linked to the two previous constituents, with planning in the making, we highlight the way in which the planning of innovation management units, and that of individuals in particular, is built on the fly. During ethnography in the CSC, we observed how it is impossible for participants to determine the milestones in the evolution of their tasks; by involving different organizational units and external partners and being independent of them, planning is interdependent and therefore changes. At a meeting, a communication technician asks about an innovation management planning. The answer is: 'Superhard... Impossible to plan something... A month? (Thinks) To tell the truth, I also see complicated. We would have a roadmap, but a long-term planning is impossible.' (A, 21/III/2016). With this type of planning, in which there are very general attainment horizons, the clarity of the task is achieved as you work on it: the deadlines are fixed in the agendas, the price forks are passed to the budgets, the initial concept are transformed into products. Thus, for these units, planning is made up of milestones that are vaguely orientated during the process of managing innovation, but that, however, the distance between milestones and their conditions to achieve those changes with time. As one of the participants warns: The planning of the projects in hand is on the fly. Some will need to accelerate when the time is right, and in others, refuel until the next point. We must always be awake if we want to reach the end of the journey' (B, 18/V/2016). Thus, the presentation to High Direction will motivate to accelerate the tasks to present some results or, on the contrary, the unavailability of some partner will delay the planning. The Innovation Project Manager must deal with such contingency of factors, and the interdependence of the agents. The interviews with the CSC showed that this planning is intrinsic to the innovation management units: it is easy toget stoned, but the recipe is to try to plan' $(1,29 / \mathrm{XI} / 2016)$. Therefore, the members of these units show a great flexibility and a very high tolerance to work in uncertain environments. 


\subsection{Level 3 (Agent) - Volatile agenda}

As in cascade, the ductile strategy triggers multifocality of these units that, at the time, reaches its maximum individual expression in the concept of volatile agendas. The attention of the organization is experienced and lived on the agendas of agents; macro-scale influences micro-scale. Following the focus of attention as a social concept, the participants' agenda are presented as a fundamental tool for structuring it. By agenda we mean the personal management of time and its usufruct during working hours and, exceptionally, private life. The day, the week and the month need to be structured temporarily in terms of commitments, meetings, deliveries and work-progress that will occupy particular time-slots. The use of time [emploi du temps] is fundamental, says Javeau (1991), because it contains key information of the lived experience of the time.

\subsubsection{Social segmentation of time}

Organizing the agenda involves distributing tasks and social relationships over time -meetings-, collective reflections on organization context, in both sense: on 'when' -when we must obtain the results, when is the ideal moment of maturity, how it fits with other initiatives- and on how many/much' -which is the importance or the scope of this innovation initiative, which are the collateral effects, how much effort required to complete it-. During a casual chat, $\mathrm{C}$ tells D: 'You have to see my agenda. It changes every day! I have a lot of things to do ... uff ... (laughs) Look, I just got another call. You neglect, and all changes suddenly. What a mess! (C, 1/IV/2016); D answers: 'Sometimes I want to answer with a 'use Doodle!' or 'see my Outlook agenda!' (D, 1/IV/2016). Days later, because of various open fronts that upset the time management: 'I cannot stretch my time any longer, you know?' (C, 25/IV/2016). Three of the SCS justified their volatile agendas with: Every task depends on the collaboration with other areas... So, your destiny is in the hands of others... The agenda is going to dance. We can try, I say 'try', to have control over that... but (sighs)' [...] (1, 5 / XII / 2016). The Innovation Project Managers work constantly with provisional: conjunctures of different nature that produce abrupt changes in their agendas. The whole set of tasks carried out by Innovation Project Managers is managed according to:

- the interrelation of tasks among themselves;

- the temporary limitations and the workload involved in undertaking them; and

- the needs of the organization as a whole. 
For its social function in the everyday life of the Innovation Project Managers, the agenda is constructed of pieces of time that Zerubavel (1991) calls 'islands of property', which means: social imposed limits in the world of phenomena in our possession. When temporal overlaps are common, our members ponder the importance of their tasks segmenting and organizing their time, the relationship between them and, in a nutshell, those of the rest of the organization; they embed in the agenda the organizational interdependencies and then diffuse attention with the personal forces. The time in organizations has a value, especially in our case studies, where not only the good organization of the organization's matters, but the anticipatory capacity. Given the scarce stability of the present and the main subject of its organization -the management of innovation, of which one of its main characteristics, according to Pavitt (2005), is uncertainty-, it favors the constant iteration toward the future, pondering different temporal scenarios defined by their choices over the present. Due to the type of tasks they carry out, these agents do not have total control over their agendas, since they are subject to a more general social framework, where each will combine the availability and the personal predisposition with the necessity and the requirements of the organization.

\subsubsection{Private calendar}

The agendas of the Innovation Project Managers are complex, mobile and interdependent. These continuous changes hinder temporal orientation and confusion of dates. To structure the time in a single narrative line that unifies the different temporal flows, the participants use the private calendar. For Sacks (2006) the private calendar relates to events of the work life with those of its personal life or with events of the external world; personal milestones or news function as temporary dating of their work agendas. Before starting a meeting: Friday, in the end, what about the meeting? I was with Coldplay [...]' (A, 30/V/2016). In interviews with the CCS: 'The last meeting I had on that topic was shortly before my sister's wedding' (3, 22/XI/2016). The personal time-line merges with the work: the dates of personal life will contribute to structuring the work-narrative by setting events -meetings, deadlines, etc.- which are difficult to locate in a time-line. 


\subsubsection{Effects}

Our blocks of time depend on the interaction we have with others (Zerubavel, 1991). Four effects of volatile agendas are:

- brownie;

- unpunctuality;

- tears; and

- multitasking.

Let's look at each one.The ethnography in the CCS showed that the participants used the word 'brownie', 'marrón' in Spanish, to refer to an activity that

- appears without prior notice;

- it is usually a requirement of higher hierarchical levels;

- it requires a short period of time to solve;

- it is outside the range of tasks performed by the organizational unit; and

- does not fit the identity of the group.

At work, A to C: 'Hurry up, hurry up! That is what he is saying with his e-mail. Why should I do that? Is it my role?' (A, 1/II/2016); C replies: I know. Be patience. But this is, it seems, the priority. Leave all that you are doing, and focus on that' (C, 1/II/2016). In the interviews, four of the SCS said the management of 'brownies' accounted for $50 \%$ of their time. Regarding unpunctuality, interviews and ethnography showed that punctuality is seldom observed in meetings; normally they start late. The beginnings and endings of meetings vary frequently. Overlap with previous or later meetings is customary. A delay will trigger concatenated delays all day or, in its most extreme case, the obligation to move the meeting to another day. It was common to hear: 'But did we start the meeting or not?' (A, 26/IX/2016). On tears, we relate to what Perlow (1999) calls 'frantic schedules', because constant uncertainty in the agendas cause states of tension. 'This week, after holidays, it's being ... I wanted to do some things, but it's impossible... I've found my 'inbox' with 98 e-mails. Can you believe it? It has no end (a bittersweet smile)' (C, 20/XI/2016). The Innovation Project Managers demonstrate great flexibility, but on certain occasions, the time breaks their personal stability. Finally, multitasking. according to Appelbaum, Marchionni and Fernandez (2008) is the simultaneous 
execution of several fragments of task at the same time with different degrees of attention, where interruptions produced by electronic gadgets are usual. The attention of these organizational agents is constantly tested. It was rare not to see in their screen several PowerPoints, Chrome windows, halftyped e-mails, draft of Words, etc. During the interviews, three of the SCSs stated that they always 'jumped' from one task to another without reaching an end. 'You begin with one thing, then another one... then another... and so on. You return to the first task and jump to the third one... You work by pieces, jumping... In the end, you finish what you are doing but with thousand jumps' (1, 29/XII/2016).

\subsubsection{Concentration}

Six of the participants ensured to keep time-slots to work without interruption in the parts of the tasks that did not depend on others. Three of the interviewees put on music not to listen to the environment; two changed space and were isolated. In very few moments, the members of these units need imperiously to focus their attention in very specific points of their tasks to progress. I run away from meetings that do not have a clear focus [...]. The agenda is mobile [...]. You can organize time as people organize their time [...]. Concentration is very important. When you are doing multitasking, if you cannot focus, you are not making good time-management. Time-management also incorporates concentration.' (1, 29/XII/2016). The focus of attention is the individual solution to diffuse attention.

\subsubsection{Solidarity}

The ravages of multifocality and volatile agendas lead to tense moments or tears in which participants had to work in solidarity. Lichterman (2005) argues that solidarity is always greater among those who are part of a group than those who are outside it. The collective affinities enhance the existence of the communal responsibility that defines their intraspecific and extra-specific solidarity. Before a brownie or a tear, the participants tended to help each other. At this point, and depending on the type of depth of the relationship between the participants, the coordination was overtaken by the rapport, which is a degree of intimacy and greater confidence. CCS and SCS stated that the closer the relationship with their peers, the easier it was to overcome the adverse moments: 'Good vibes are essential' (5, 7/XII/2016). All without exception stress that if, in addition to the good work consonance -coordination- there is added confidence in the personal sphere -penetration-, there is a solidarity that has a positive impact on the management of innovation. From what we can infer, solidarity is postulated as a decisive 
variable, since it strengthens the bonds of union between the members of these units and is the way in which, collectively, the diffuse attention is overcome.

\section{Conclusions}

The emergent theory shows us, and we repeat it, in this cascade movement: the diffuse attention of an organization promote that the innovation management units experience the multifocality and, at personal level, the agendas become volatile. The empirical work confirms this cascade movement of attention at three levels, which we have analyzed in detail and highlighted those constituents that are given in the everyday life of the real practices of innovation management. In everyday life, it is worth remembering that agents embody the discourses of structure in their practices, attitudes and in their own bodies (Collins, 2004; De Certeau, 2006; Fine \& Scott, 2011). As a result, a diffused attention to macroscale impacts the lives of individuals who manage innovation. If innovation management must materialize innovation opportunities, reduce investment risks, assess technical and operational feasibility and weigh its future impact, the concentration of attention is fundamental. On the other hand, we find it much more difficult to validate in the reality that the opposite movement exists (retro-cascade movement). This movement would go from level 3 to level 1: when the agendas of the agents are volatile, the attention of the unit suffers from multifocality and, at organizational level, from diffuse innovation. This movement can be inferred but not firmly stated. It remains for future research.

As a result of microsociological research, our emergent theory contains concepts such as ductile strategy, open fronts, fragmented vision, volatile agenda, etc., which allow us to shed new light on innovation management; this is extremely dynamic and convulsive, very interdependent on the social sense, never linear and always iterable and, above all, open: open to collaboration with others, openminded to explore new combinations and open for the uncertainty of multiple paths of an idea -the intangible- in its way to the market -the tangible-. These are aspects that could be studied with renewed forces in new exploration of innovation management. Take these pages as a point de depart. 


\section{References}

Agar, M. (2004). The Professional Stranger: An Informal Introduction to Ethnography. Orlando: Academic Press.

Allen, M.R., Adomza, G.K., \& Meyer, M.H. (2015). Managing for Innovation: Managerial Control and Employee Level Outcomes. Journal of Business Research, 68(2), 371-379.

https://doi.org/10.1016/j.jbusres.2014.06.021

Alter, N. (2013). L'InnovationOrdinaire. París: PUF.

Amabile, T.M, Conti, R., Coon, H., Lazenby, J., \& Herron, M. (1996). Assessing the Work Environment for Creativity. Academy of Management Journal, 39(5), 1154-1185. https://doi.org/10.2307/256995

Appelbaum, S.H., Marchionni, A., \& Fernandez, A. (2008). The Multi-tasking Paradox: Perceptions, Problems and Strategies. Management Decision, 46(9), 1313-1325. https://doi.org/10.1108/00251740810911966

Baregheh, A., Rowley, J., \& Sambrook, S. (2009). Towards a Multidisciplinary Definition of Innovation. Decision, 47(8), 1323-1339. https://doi.org/10.1108/00251740910984578

Casey, C. (2002). Critical Analysis of Organizations: Theory, Practice, Revitalization. Londres: SAGE.

Charmaz, K. (2006). Constructing Grounded Theory. A Practical Guide through Qualitative Analysis. Thousand Oaks: SAGE.

Cheng, Ch.-F., Chang, M-L, \& Li, Ch.-S. (2013). Configural Paths to Successful Product Innovation. Journal of Business Research, 66(12), 2561-2573. https://doi.org/10.1016/j.jbustes.2012.10.006

Chesbrough, H.W. (2003a). Open Innovation: The New Imperative for Creating and Profiting from Technology. Boston: Harvard Business School Press.

Chesbrough, H.W. (2003b). The Era of Open Innovation. MIT Sloan Management, 44(3), 35-41.

Cho, T.S., \& Hambrick, D.C. (2006). Attention as a Mediator Between Top Management Team Characteristic and Strategic Change: The Case of Airline Deregulation. Organization Science, 17(4), 453-569. https://doi.org/10.1287/orsc.1060.0192

Collins, R. (2004). Interaction Ritual Chains. Princeton: Princeton University Press. https://doi.org/10.1515/9781400851744

Crane, F., \& Meyer, M. (2011). The Challenges of Innovation in American Companies: An Executive Ethnographic Investigation. Journal of Technology Management \& Innovation, 6(4), 193-204. https://doi.org/10.4067/S0718-27242011000400014 
Creswell, J.W. (2009). Research Design. Qualitative, Quantitative, and Mixed Methods Approaches. Los Angeles, Londres, Nueva Delhi \& Singapur: SAGE.

Damanpour, F., \& Gopalakrishnan, S. (1998). Theories of Organizational Structure and Innovation Adoption: The role of environmental change. Journal of Engineering Technology Management, 15(1), 1-24. https://doi.org/10.1016/S0923-4748(97)00029-5

De Certeau, M. (2006). La Invención de lo Cotidiano 1. Formas de Hacer. México D.F: Universidad Iberoamericana.

Díaz, P. (2014). From 'Infoxication' to 'Infosaturation': A Theoretical Overview of the Cognitive and Social Effects of Digital Immersion. Ámbitos, 24. Available online at: http://repositorio.ucp.pt/bitstream/10400.14/14939/1/PD_Infoxication_2014.pdf

Dorado, S. (2013). Small Groups as Context for institutional Entrepreneurship: An Exploration of the Emergence of Commercial Microfinance in Bolivia. Organizational Studies, 34(4), 533-557. https://doi.org/10.1177/0170840612470255

Eisenhardt, K.M. (1989). Building Theories from Case Study Research. Academy of Management Review, $14,532-550$.

Fagerberg, J. (2005). Innovation: Guide to the Literature. In: J. Fagerberg, D.C. Mowery R.R. \& Nelson (eds.). The Oxford Handbook of Innovation. Oxford: Oxford University Press.

Fine, G.A. (2012). Tiny Publics. A Theory of Group Action and Culture. Nueva York: Rusell SAGE Foundation.

Fine, G.A., \& Scott, L.-J. (2011). Wispy Communities: Transient Gatherings and Imagined microcommunities. American Behavioral Scientist, 55(10), 1319-1335. https://doi.org/10.1177/0002764211409379

Gioia, D.A, Schultz, M., \& Corley, K. (2000). Organizational Identity, Image, and Adaptative Inestability. Academy Management Review, 25, 63-81.

Glaser, B.G., \& Strauss, A.L. (1967). The Discovery of Grounded Theory: Strategies for Qualitative Research. Chicago: Aldine.

Godin, B. (2015). Models of Innovation: Why models of Innovation are models, or What Work Being Done in Calling Them Models?. Social Studies of Science, 45(4), 570-596. https://doi.org/10.1177/0306312715596852

Hamel, G. (2006). The Why, What, and How of Management Innovation. Harvard Business Review, February. 
Hamel, G. (2007). The Future of Management. Boston: Harvard Business School Press.

Hammersley, M., \& Atkinson, P. (2007). Ethnography: Principles in Practice. Londres \& Nueva York: Routledge.

Hogan, S., \& Coote, L.V. (2014). Organizational Culture, Innovation, and Performance: A test of Schein's Model. Journal of Business Research, 67(8), 1609-1621. https://doi.org/10.1016/j.jbusres.2013.09.007

Javeau, C. (1991). Au Degré Zéro de la Vie Quotidienne. Bruxelles: De Boeck.

Kim, L. (1980). Organizational Innovation and Structure. Journal of Business Research, 2(8), 225-245. https://doi.org/10.1016/0148-2963(80)90012-0

Ladner, S. (2014). Practical Ethnography. A Guide to Doing Ethnography in the Private Sector. Walnut Creek: Left Coast Press.

Lawson, B., \& Samson, D. (2001). Developing Innovation Capability in Organisations: A Dynamic Capabilities Approach. International Journal of Innovation Management, 5(3), 377-400. https://doi.org/10.1142/S1363919601000427

Lichterman, P.R. (2005). Elusive Togetherness: Church Groups Trying to Bridge America's Divisions. Princeton: Princeton: University Press. https://doi.org/10.1515/9781400842957

March, J.G., \& Simon, H.A. (1958). Organizations. Nueva York: Wiley.

Michaud, Th. (2012). L'Utilité de la Sociologie pour Comprendre le Passage de l'Imaginaire à l'Innovation dans les Organisations. Cahiers de Recherche Sociologique, 53, 215-234. https://doi.org/10.7202/1023197ar

Ocasio, W. (1997). Towards an Attention-Based View of the Firm. Strategic Management Journal, 18, 187-206. https://doi.org/10.1002/(SICI)1097-0266(199707)18:1+<187::AID-SMJ936>3.3.CO;2-B

Ocasio, W. (2011). Attention to Attention. Organization Science, 22(5), 1286-1296. https://doi.org/10.1287/orsc.1100.0602

Patton, M.Q. (1989). Qualitative Evaluation Methods. Beverly Hills: SAGE.

Pavitt, K. (2005). Innovation Process. In: J. Fagerberg, D.C. Mowery, R.R. Nelson (eds.). The Oxford Handbook of Innovation. Oxford: Oxford University Press.

Perlow, L.A. (1999). The Time Famine: Towards a Sociology of Work Time. Administrative Science Quarterly, 44, 57-81. https://doi.org/10.2307/2667031

Porter, M.E. (1996). What is Strategy?. Harvard Business Review, 74(6), 61-78. 
Rothwell, R. (1994). Towards the Fifth-Generation Innovation Process. International Marketing Review, 11(7), 7-31. https://doi.org/10.1108/02651339410057491

Ryan, J.C., \& Tipu, S.A.A. (2013). Leadership Effects on Innovation Propensity: A two Factors range Leadership Model. Journal of Business Research, 66(10), 2116-2129. https://doi.org/10.1016/j.jbusres.2013.02.038

Sacks, H. (2006). Lectures on Conversation (Volume I \& II). Edited by Gail Jefferson, with an Introduction by Emanuel A. Schegloff. Oxford: Blackwell.

Scheff, Th.J. (2007). Microsociology. En: G.Ritzer (ed.). The Blackwell Encyclopedia of Sociology. Oxford, Nueva York \& Victoria: Blackwell Publishing.

Seidman, I. (2006). Interviewing as Qualitative Research. A Guide for Researchers in Education and the Social Sciences. Nueva York: Teachers College Press.

Strauss, A., \& Corbin, J. (1998). Basic Qualitative Research: Techniques and Procedures for Developing Grounded Theory. ThousandOaks: SAGE.

Taylor, S.J., \& Bogdan, R. (1987). Introducción a los Métodos Cualitativos de Investigación. La Búsqueda de Significados. Barcelona: Paidós.

Tidd, J., Bessant, J., \& Pavitt, K. (2011). Managing Innovation: Integrating Technological, Market and Organizational Change. Nueva York: Wiley.

Un, C.A. (2011). Research Notes and Commentaries: the advantage of Foreignness in Innovation. Strategic Management Journal, 32(11), 1232-1242. https://doi.org/10.1002/smj.927

Van Maanen, J., \& Barley, S.R. (1985). Cultural Organization: Fragments of a Theory. In: P.M. Frost, L.F. Moore, M.R. Louis, C.C. Lundberg \& J. Martin (eds.). Organizational Culture. Beverly Hills: SAGE.

Vila, L.E., Pérez, P.J., \& Coll-Serrano, V. (2014). Innovation at the Workplace: Do Professional Competencies Matter?. Journal of Business Research, 67(5), 752-757. https://doi.org/10.1016/j.jbusres.2013.11.039

VolkanTürker, M. (2012). A Model Proposal Oriented to Measure Technological Innovation Capabilities of Business Firms - a Research on Automative Industry. Procedia, 41, 147-159.

Yin, R.K. (2011). Qualitative Research from Start to Finish. Nueva York \& Londres: Guilford Press. 
Zahra, S.A., \& Covin, J.G. (1994). The Financial Implications of Fit between Competitive Strategy and Innovation Types and Sources. The Journal of High Technology Management Research, 5(2), 183-211. https://doi.org/10.1016/1047-8310(94)90002-7

Zerubavel, E. (1991). Islands of Meaning. In: J.A. O'Brien (ed.). The Production of Reality: Essays and Readings on Social Interaction. Los Ángeles: SAGE.

Intangible Capital, 2017 (www.intangiblecapital.org)

Article's contents are provided on an Attribution-Non Commercial 3.0 Creative commons license. Readers are allowed to copy, distribute and communicate article's contents, provided the author's and Intangible Capital's names are included. It must not be used for commercial purposes. To see the complete license contents, please visit http://creativecommons.org/licenses/by-nc/3.0/. 